\title{
PREVALENCE AND HISTOPATHOLOGY OF TRICHINELLA SPIRALIS LARVAE OF SLAUGHTERED PIGS IN CAIRO GOVERNORATE, EGYPT
}

\author{
By \\ AHMED K. DYAB ${ }^{1^{*}}$, MARWA A. AHMED ${ }^{2}$, and AHMED G. ABDELAZEEM ${ }^{3}$ \\ Department of Parasitology ${ }^{1}$, Faculty of Medicine Assiut University, Department \\ of Pathology ${ }^{2}$ and Department of Parasitology ${ }^{3}$, Faculty of Veterinary Medicine, \\ Aswan University, Egypt ( ${ }^{*}$ Correspondence: ahmedsaf2001@yahoo.com)

\section{Abstract} \\ The present work was planned to study the prevalence and the pathological lesions of Trichinel- \\ la spiralis larva of slaughtered pigs in Cairo Governorate by using Trichinoscopic examination \\ in slaughterhouse and confirmatory diagnosis by histopathological examination. For this purpose \\ 184 muscle samples of pigs were collected from Al-Basatin Slaughterhouse, Cairo Gover- \\ norate. The overall prevalence of Trichinella spiralis infection was $1.08 \%$ of examined pig's car- \\ casses.
}

Key words: Trichinella spiralis, Pig, Trichinoscopy, Histopathology.

\section{Introduction}

Trichinellosis is one of the most widely distributed parasitic zoonosis worldwide and is caused by infection with nematodes of the genus Trichinella (Conlan et al, 2014). Trichinella spiralis infect a broad variety of mammals, birds and reptiles and are distributed worldwide. Human infections occur after ingestion of raw or inadequately cooked meat containing parasite larvae. Pigs represent a major source of human infection (Pannwitz et al, 2010). It can be a serious disease, particularly in the elderly, where severe complications such as myocarditis or encephalitis can lead to death (Djurkovic et al, 2013)

The prevalence of the parasite in swine in some regions of the world is a public health concern (Gajadhar et al, 1997). Also represents an economic problem in porcine animal production and food safety (Gottstein et al, 2009).When the role of pigs in the trichinellosis cycle was definitively established in the 1860s, it became imperative to monitor the development of the disease in both animals and humans (Blancou, 2001). Trichinella infection rarely causes clinical signs in the parasite's natural hosts, unless they are infected with a very large number of larvae (Bruschi and Murrell, 2002). T. spiralis is diagnosed by detecting $T$. spiralis larvae in muscle samples or by testing for the presence of Trichinella antibodies in the serum or in the meat juice
(Gottstein et al, 2009). In pigs, establishment of the larvae of $T$. spiralis results in extensive disturbances at the cellular level and consequent pathological changes in skeletal muscles and organs (Ribicich et al, 2007). This study aimed to assess the percentage of infection and pathological lesions of Trichinella spiralis larvae in pig slaughtered in Governom- ental Slaughterhouse, Cairo Governorate.

\section{Materials and Methods}

Study design and sampling: A total of 184 muscle samples (mainly diaphragm and skeletal muscle) were collected over a period of 6 months on days of slaughtering pigs from December 2018 to May 2019, in AlBasatin Slaughterhouse, Cairo Governorate. Egypt.

I- Postmortem examination: 1- Trichinoscopy or compression method: Traditional way of analyzing meat for Trichinella larvae in slaughterhouse, is to use a compressorium or trichinoscopy and performed as follow; One gram of diaphragm or $\mathrm{m}$. masseter is cut into small pieces.After being placed between the glass plates of the compressorium, the plates were screwed tightly together, so the meat was pressed into a thin, transparent layer. The compression was examined directly in the dissection binocular microscope (Roepstorff and Nansen, 1998).

2-Histopathological examination: Specimens from muscle of infested pigs were recovered and fixed in $10 \%$ formaline solution 
for histopathological examination. After ensuring the complete fixation, the specimens were washed with tape water, dehydrated in ascending series of ethanol up to absolute alcohol, cleared in xylene and embedded in paraffin. Section of 5 micron thickness were prepared and stained with Hematoxylin \& Eosin (Hassanin et al, 2013).

II- Experimental animals: 1- Laboratorybred parasite-free male Swiss Albino mice, 6-8 weeks old, weighing 25-30g each were used. The animals were purchased from (Animal House, Faculty of Medicine, Assiut University, Egypt).

2- Experimental infection of mice: The larvae of $T$. spiralis were isolated from the infected pork meat obtained from the muscle samples (mainly the diaphragm and skeletal muscles) from El-Basatin Slaughterhouse, Cairo Governorate. The infected samples were put in the digesting fluid (1\% pepsin and $1 \% \mathrm{HCL}$ in $200 \mathrm{ml}$ distilled water). The mixture was incubated at $37^{\circ} \mathrm{C}$ for an hour under continuous agitation using an electric stirrer. The outcome digested product was passed through a 50-mesh/inch sieve to remove the coarse particles. Encysted larvae were collected on a 200-mesh/inch silver sieve, washed twice with tap water and then suspended in $150 \mathrm{ml}$ of tap water in a conical flask. The supernatant fluid was discarded and the larvae were collected by Pasteur pipettes. Mice were infected with $T$. spiralis larvae orally and were housed in appropriate insect proof-cages and fed in the accordance with the institutional and national guidelines. They were kept under close observation. On the $35^{\text {th }}$ day post infection, the infected mice's were sacrificed by their neck dislocation.

The small intestine of each mouse was removed, dissected longitudinally, washed and the $T$. spiralis adult worms were detected and their muscles were digested for larval detection the sediment reconstituted in 3-5 drops of saline, and then examined drop by drop at a magnification of 20X (Yang et al, 2014).

\section{Results}

Prevalence of trichinellosis: The results showed that the prevalence of $T$. spiralis larvae infection in the slaughtered pigs, from El-Basatin Slaughterhouse was 2 out of 184 (1.08\%).

Histopathology examination; encysted larvae were replacing in the muscle fibers and inflammation was minimal to absent consisting of few lymphocytes.

The details were given in figures $(1,2,3$, $4,5,6 \& 7)$.

\section{Discussion}

Prevalence: However, domestic trichinellosis (Trichinella spiralis) is present in Egypt. Few reports of $T$. spiralis infection in fresh and processed pork in Egypt are available (Youssef and Uga, 2014). The present study revealed that the prevalence of Trichinella spiralis larvae infection in slaughtered pigs, in Albasatin slaughterhouse in Cairo Governorate (Egypt), was 1.08\% (2/184), the lowest infection rate in this study agree with mentioned by Abdel-hafeez et al. (2015) in El-Minia (Egypt), who concluded that, no pig was infected with $T$. spiralis by using the different techniques throughout the governorate. The results were lower than that of Sayed et al. (2010) in Upper Egypt, who detected the infection rate of $5 \%$ \& $2 \%$ in Assiut and Sohage Governorates, respectively. Conlan et al. (2014) in Laos (Australia) reported trichinellosis in $2.1 \%$ of examined pigs. The low prevalence rate of infection with trichinellosis in pigs might be related to hygienic conditions for rearing pigs in private farms or large farm and rising of the Egyptian pigs is mainly indoors away from the sources of infection. No doubt, lack of accuracy in slaughterhouses during examination of pig carcasses depending on trichinoscopy, which is of more or less not dependable accuracy and need well a trained technician. Djurkovic et al. (2013) reported that the trichinoscopy gave a sensitivity of around one larva/ gram, which was not accepted to exclude trichinosis infection. 
In the present study, hstopathological examination revealed that, encysted larvae were replacing the muscle fibers and inflammation is minimal to absent minimal inflammation consisting of few lymphocytes. This result agreed with Zachary and McGavin (2012) who reported that after the cyst formation, the larvae are protected from the hosts' immune response and inflammation is minimal to absent other than focal inflammation consisting of eosinophils, neutrophils, and lymphocytes occur associated with invasion of muscle by Trichinella larvae. Wu et al. (2008) found that Trichinella spiralis larvae build their own home in the infected muscles. The home is a capsule composed of a collagenous wall and cellular components. The wall provides some protection to the parasite and the cellular component that takes care of the parasites in terms of metabolism. Because of its function, the name "nurse cell" has been given to the cellular components. A series of recent studies provide more evidence to strengthen their ideas that Trichinella utilizes a repairing process of muscles cells to construct the capsule. In other words, after injury induced by parasite invasion, muscle cells start going through the process of repair, just like after any trauma. Trichinella sp. larva borrows only the initial part of this repair process to construct its own home. Since the satellite cell is a progenitor cell located within the capsule wall, a new cell can be continuously supplied from the myoblast, even if the present nurse cell dies. This explains why the nurse cell looks intact and active for years in spite of intracellular parasitism. Sometimes, the presence of nurse cell-parasite complex indicates the ongoing infection. A mature capsule and a coiled parasite indicate an older infection (Capo and Despommier, 1996).

Generally, worldwide about 10,000 trichinosis infections occur a year. At least 55 countries including the United States, China, Argentina, and Russia have had been reported cases (CDC, 2015). Trichnosis occurs in the tropics is less common (Jeremy,
2013). Trichinosis rates in USA decreased from 400 cases/year in 1940s to 20 or fewer /year in 2000s (CDC, 2016).

\section{Conclusion}

Pigs are the main reservoir of trichinellosis, but their role depends on their breeding. In large farms infested rodent and did not apply hygienic programmes, pig meat must be thoroughly examined in slaughterhouse and properly cooked before consumption.

\section{References}

Blancou, J, 2001: History of trichinellosis surveillance. Parasite 8:S16-9.

Capo, V, Despommier, DD, 1996: Clinical aspects of infection with Trichinella spp. Clin. Microboil. Rev. 9, 1:47-54.

CDC, 2015: Trichinellosis: Prevention \& Control. www.cdc.gov. Archived from the original on 2015-09-24: Retrieved 2015-07-25.

CDC, 2016: Trichinellosis Fact Sheet-Divis-ion of Parasitic Diseases. August 2012: Archived from the original on 2016-05-22.

Conlan, JV, Vongxay, K, Khamlome, B, et al, 2014: Patterns and risks of Trichinella infection in humans and pigs in northern Laos. PLOS Negl. Trop. Dis. 8, 7:1-9.

Djurkovc, O, Bobic, B, Nikolic, A, et al, 2013: Pork as a source of human parasitic infection. Clin. Microbiol. Infect. 19:586-94.

Hassanin, FS, Shaltout, FAE, Afifi, MEM, 2013: Parasitic affections in edible offal. Benha Vet. Med. J. 25, 1:46-55.

Gajadhar, AA, Bisaillon, J, Appleyard, GD, 1997: Status of Trichinella spiralis in Domestic Swine and Wild Boar in Canada. Can. J. Vet. Res. 61:256-9.

Gottstein, B, Pozio, E, Nockler K, 2009: Epidemiology, diagnosis, treatment, and control of trichinellosis. Clin. Microbiol. Rev. 22:127-42.

Jeremy, F. 2013: Manson's Tropical Diseases $\left(23^{\text {th }}\right.$ Ed.). Philadelphia: Saunders (Imprint): ISBN 978-0-7020-5101-2.

Pannwitz, G, Mayer, A, Balicka, A, Nöckler K, 2010: Increased Prevalence of Trichinella spp., Northeastern Germany. Emerg. Infect.

Dis. 16, 6:936-42.

Roepstorff, A, Nansen, P, 1998: Epidemiology, diagnosis and control of helminthic parasites of swine. In: Animal Health Manual $3^{\text {rd }}$ ed. FAO, WHO.

Sayed, ASM, Hussein, AAA, Arafa, MI, et al, 2010: Epidemiological study on trichinellosis in 
pigs and man in Upper Egypt. Assi. Vet. Med. J. 56, 125:280-7.

Wu, Z, Milosavljevic, L, Nagano, I, et al, 2008: Trichinella spiralis: nurse cell formation with emphasis on analogy to muscle cell repair. Parasites Vectors 1:27-30.

Yang, Y, Qin, W, Qui, H, et al, 2014: Chara- cterization of TsDAF-21/HSP90 protein from parasitic nematode Trichinella spiralis. Parasitol. Res. 113:2209-17.

Youssef, AI, Uga, S, 2014: Review of parasitic zoonoses in Egypt. Trop. Med. Hlth. 42, 1: 3-14.

Zachary, JF, McGavin, MD, 2012: Pathologic basis of veterinary disease. $5^{\text {th }}$ Edition.

\section{Explanation of figures}

Fig. 1: Encysted larva of Trichinella sp. in muscle tissue of pig with minimal inflammation consisting of few lymphocyte and degeneration in muscle showing loss of cross stration and become more eosinophilia (arrow) (H\&E stain $\mathrm{x} 400)$.

Fig. 2: Muscle biopsy from pig infected with trichinellosis a) minimal Cellular infiltrates; b) Collagen capsule of nurse cell; c) Intersected muscle larva (H\&E stain x200).

Fig. 3: Calcified cyst within muscle tissue of pigs (H\&E stain $x 100)$.

Fig. 4: Trichinella spiralis larvae encysted in muscle (after inflammatory cell reaction subsided). (H\&E stain x100).

Fig. 5: Encysted larva within muscle fibers of pig infected with trichinellosis. (after inflammatory cell reaction subsided) (H\&E stain x200).

Fig. 7: Adult T. spiralis obtained from small intestine of mice infected experimentally with larva of $T$. spiralis (Unstained specimen).
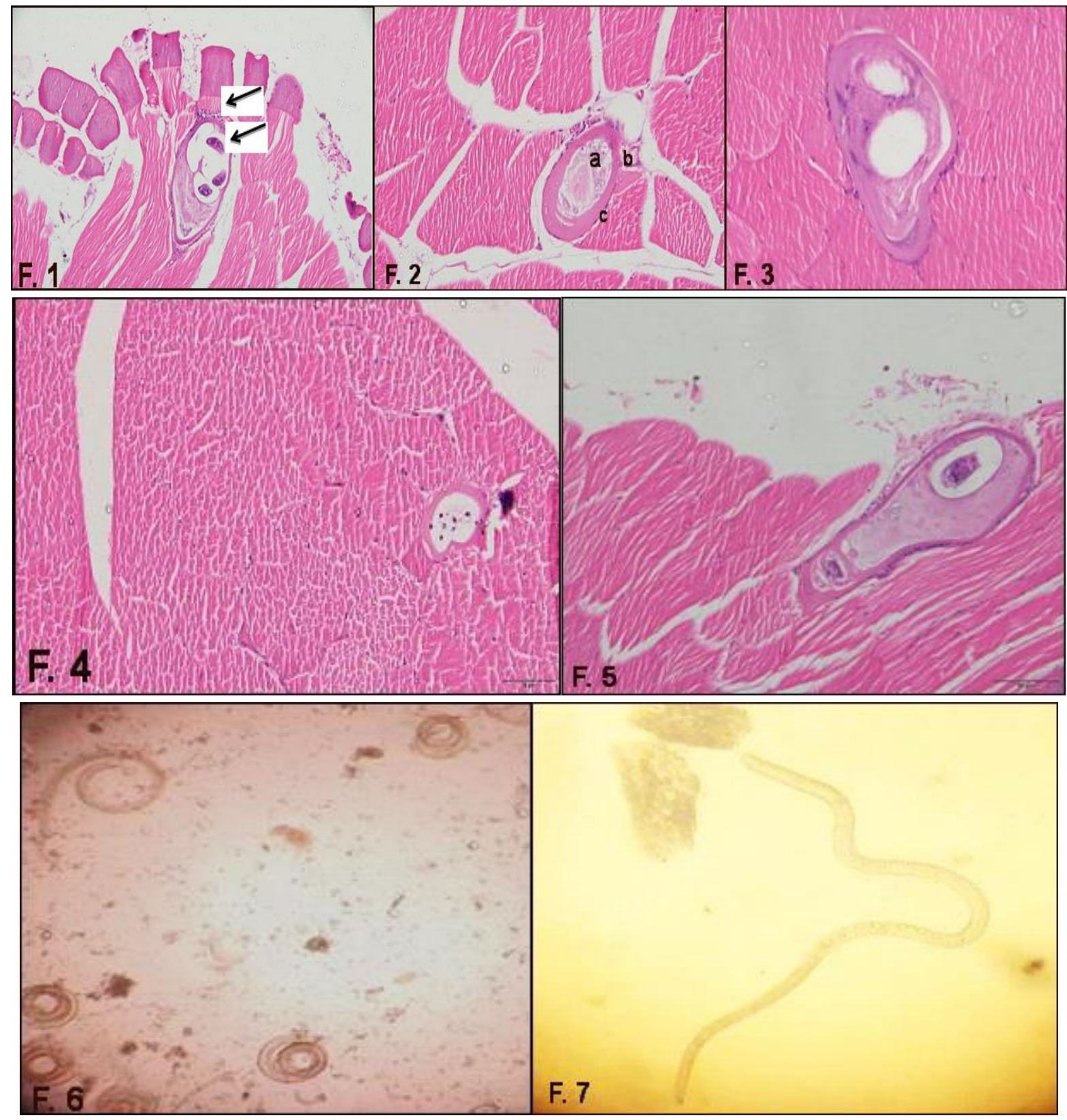